\title{
Obstinate Club Foot with Triple Plus Dislocations
}

\author{
Rattan Lal Mittal
}

\section{ABSTRACT}

Resistant/rigid club foot, a common orthopedic problem, still remains an unsolved problem, especially, when we come across deformities in older children, adolescents or adults, after multiple surgeries and sometimes unique cases, like this one. This case had unique pathoanatomy, due to congenital factors, increasing age and persisting with vengeance in spite of two earlier surgeries. Before planning another surgery, it was imperative to diagnose the actual cause, i.e. the unique pathoanatomy. Various other surgical options were not expected to give the desired result due to this unique pathoanatomy. The author has been in club foot research since long and the concept of this research has been based on pathoanatomy and its total correction. During this research process, there have been numerous need based modifications from time to time, based on applied interpretations of pathoanatomy, to make it effective in all resistant club feet, at any age, including adolescents and adult, which have been used in a large series with adequate follow-up in the past 25 to 30 years, with gratifying results. The landmark modifications have been: giving a generic name obstinate club foot given to every imaginable rigid club foot of any age, a substitute for multiple names found in literature; surgical technique named as Dolarz technique incorporating Z-plasties in dorsolateral rotation skin flap (DOLAR); a modification of the earlier technique already reported in the literature and not likely to succeed. Besides the skin flap, the modified extended deeper extensive soft tissue and osseous release was named as subtotal subtalar release (SSR). Treatment of the present case was by Dolarz technique, with some newer modifications. Each step was more extensive focusing on triple plus dislocations, including an innovative sliding osteotomy of cuboid for complete correction. Awareness for diagnosis and good preoperative planning was essential for gratifying result.

Keywords: Obstinate club foot, Recurrent and rigid, Subtotal subtalar release, Dolarz surgical technique, Club foot.

How to cite this article: Mittal RL. Obstinate Club Foot with Triple Plus Dislocations. J Foot Ankle Surg (Asia-Pacific) 2014;1(2):72-77.

Source of support: Nil

Conflict of interest: None

Former Professor and Head

Department of Orthopedics, Government Medical College Patiala, Punjab, India

Corresponding Author: Rattan Lal Mittal, Former Professor and Head, Department of Orthopedics, Government Medical College, $97 \mathrm{New}$ Lal Bagh Colony (Opposite Polo Ground) Patiala, Punjab, India, Phone: +91-9417469164, e-mail: mittalrl@yahoo.co.in

\section{INTRODUCTION}

Idiopathic congenital club foot, although a common orthopedic problem, yet it remains unsolved. There are numerous, often confusing, terms in literature for problematic club feet, e.g. neglected, recurrent, relapsed, residual, resistant, recalcitrant, severe, rigid, etc. having common difficulties of treatment and failures. There are controversies in pathoanatomy. Some put primary blame on the muscles, ${ }^{1-3}$ others to bones, mainly talus ${ }^{4-6}$ and still others to both muscles and bones. ${ }^{7}$ Subluxation or dislocation of talonavicular joint was stressed by Turco ${ }^{8}$ and Simons. ${ }^{9}$ In management too, there are innumerable surgical procedures and their modifications in literature, i.e. partial and complete subtalar release ${ }^{8,9}$ respectively, Hippocrates $^{10}$ stated there are more than one type of club feet'. Ponseti's plaster casting technique and its modifications, ${ }^{11}$ calcaneocuboid fusion, ${ }^{12}$ tarsometatarsal mobilization, ${ }^{13}$ metatarsal osteotomies, ${ }^{14}$ lateral release, ${ }^{15}$ early posteromedial release in first 3 months, ${ }^{16}$ Ilizarov technique with various modifications, ${ }^{17,18}$ talectomy, ${ }^{19}$ etc. In spite of vast literature, recurrence rate is still high, 36 to $68 \%{ }^{20,21}$ in different series and a satisfactory and universal solution is still not available.

Sometimes one comes across unique problems. They present a diagnostic as well as therapeutic enigma. Author has been getting difficult and problem club feet off and on. One such case treated sometimes back, neither seen earlier nor reported in literature, is being described in this paper.

In 1987, a surgical correction in resistant club feet in small children was published, based on patho-anatomy, ${ }^{22}$ correcting the skin contracture by rotation skin flap and extensive soft tissue release ${ }^{23}$ with good results. Although a good and rational technique in small children, especially first timers; yet this could not achieve good corrections in older children, adolescents, adults, previously operated with scars, even in younger children with very severe deformities frequently seen in developing countries and in some unusual cases, neither seen earlier nor reported like the present case. Faced with a need based such difficult problems, this technique needed some modifications to achieve gratifying results in such situations. The

Note: This unique case report, seen recently, is a continuation of about 50 years research work, which was awarded by Indian Orthopedic Association, Silver Jubilee Award in 1988 for original research, published in International Orthopedics (SICOT-1987). This research was upgraded after that with numerous modifications to enhance its efficacy and bagged Golden Jubilee Award too in 2013 and these lectures were delivered at Madurai and Agra-India, at the annual conferences of IOA, respectively. This work has also been presented at many other International Conferences, besides SICOT and WPOA. 
author has been in club foot research for about 50 years with good experience in correcting difficult deformities, which is based on study of pathoanatomy and its applied interpretations. There have been many milestones in this endeavor: Pathoanatomy being 3D, so correction too 3D; giving a rational generic name obstinate given to any imaginable problematic club feet at any age, a substitute for multiple terms found in literature; a crisp name of Dolarz surgical technique, derived from its initial letters (dorsolateral skin flap rotation with z-plasty added to it; tibialis posterior considered as the most important factor in pathoanatomy and every thing else secondary (evidence based); a terse nameSSR, abbreviation of subtotal subtalar release given to this extensive soft tissue and osseous release as against partial and complete subtalar releases reported in literature. Thus, evidence based, step by step, total correction of obstinate deformities at any age, by Dolarz surgical technique was evolved.

\section{EVIDENCE}

It will be important to describe the complete evidence, based on the applied interpretations of pathoanatomy of this deformity, in order to understand the rationale behind this extensive surgical technique.

- Skin contracture on posteromedial aspect: On passive manipulation, skin becomes tight on posteromedial side and loose on dorsolateral side. It increases with age due to adaptative changes. Scars of previous surgeries, with persisting deformities, further increase the contracture. The simulated two circle diagram on the deformed specimen further proves it (Fig. 1).

- Muscular contractures: Tibialis posterior, with its nine tenacious insertions, strongly pulling the foot bones toward medial malleolus, has been considered as the single most important factor in the patho-anatomy and rest every thing (skin, other soft tissues, ligaments, capsules and bones and joints) follow it and can be explained on this basis. Abductor hallucis, gastrosoleus, short and long flexors of toes too follow suit along with plantar aponeurosis.

- Ligamentous contractures: Conjoint posterior capsule of ankle and subtaloid joints, spring ligament, plantar intertarsal and tarsometatarsal as well as interosseous talocalcanean ligament are all contracted.

- Bones and joints: Talonavicular subluxation/dislocation, adaptative changes of age and weightbearing lead to overgrowth on dorsolateral aspect, in the calcaneocuboid area, with increasing rigidity of deformity. With all these, in a classical deformity with equinus, adduction, inversion and cavus; any one or more or all may predominate in varying proportions. Scars of previous surgeries further complicate the deformity. It is a three-dimensional (3D) deformity from skin to the deeper tissues and, hence, will require a 3D incision (Fig. 2) incorporating Z-plasties whenever required, for all round (3D) correction, which will be described with this case report along with requisite specific modifications.

\section{CASE REPORT}

This is the first such case with unique pathoanatomy seen in the last more than 50 years and to the best of my knowledge, no such case has been reported in the literature.

- Clinical features: This was a 9 and half years old male with a very rigid equinocavovarus deformity of right foot with adherent bow string keloid scars of two earlier surgeries at 6 months and 7 years, and a widened ankle mortise as compared to the left foot, suggesting tibiofibular diastasis (Fig. 3).

- Skiagrams (AP and lateral) and MRI: They showed a flat topped talus with a triple plus sublux/dislocations (cuneonavicular, talonavicular and anterior dislocation of talus both at ankle and subtaloid joints with inferior tibiofibular diastasis). Lower end of fibula lying far posterior to lower end of tibia in lateral X-ray as compared to normal and MRI confirming the clinical impression of diastasis. This has been called triple plus dislocations, because the talar dislocation was not a simple one, but at both at ankle and subtaloid joints with additional diastasis (Fig. 4). The flow chart explains these dislocations at a glance (Fig. 5).

- Surgical correction: Dolarz surgical technique along with SSR is given in detail so that others can follow.

- Skin contracture: This was a 3D incision, a crooked hockey-shaped incision was given, starting near the base of 5 th metatarsal in a semicircular fashion over the dorsum, going medially near tendoachilles insertion and then along its medial side for about 4 inches, incorporating two Z-plasties and excision of previous scars (Fig. 6). A thick flap of skin along with subcutaneous tissues was raised, undermining the minimum for about $1.5 \mathrm{~cm}$ only, meticulously preserving the vasculature, to avoid necrosis of flap.

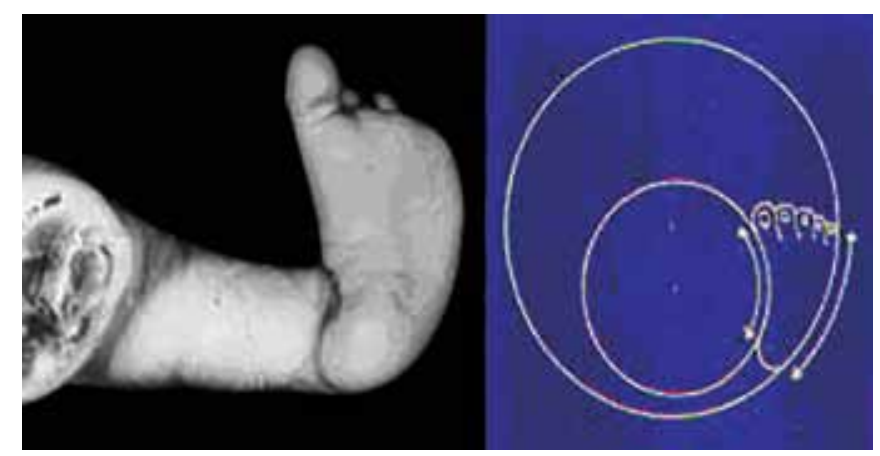

Fig. 1: A deformed cadaver foot with a simulated two circle diagram showing medial contracture 
- Muscular contractures: After completely sliding forward, the unusual grossly hypertrophied abductor hallucis from its origin (Fig. 7), the rest of all deeper correction was done: $Z$ lengthening of tendoachilles, Steindler's release, meticulous division of all nine insertions of tibialis posterior from the depth of the sole of foot (Fig. 8), division of flexor hallucis longus and flexor digitorum at the knot of Henry.

- Ligamentous contractures: Ligamentous contractures were released, i.e. division of spring ligament completely from medial to lateral side as well as other plantar intertarsal and tarsometatarsal ligaments to open up crowded foot bones; complete division of conjoint posterior capsule of ankle and subtaloid joints from medial to lateral side to open up the ankle and subtaloid joints with freely visible posterior end of talus with free movements at both joints under vision; subtotal subtalar release of interosseous talocalcanean ligament blindly by inserting a stab knife in the sinus tarsi from lateral side (Fig. 9) and giving an anteroposterior sweep thus
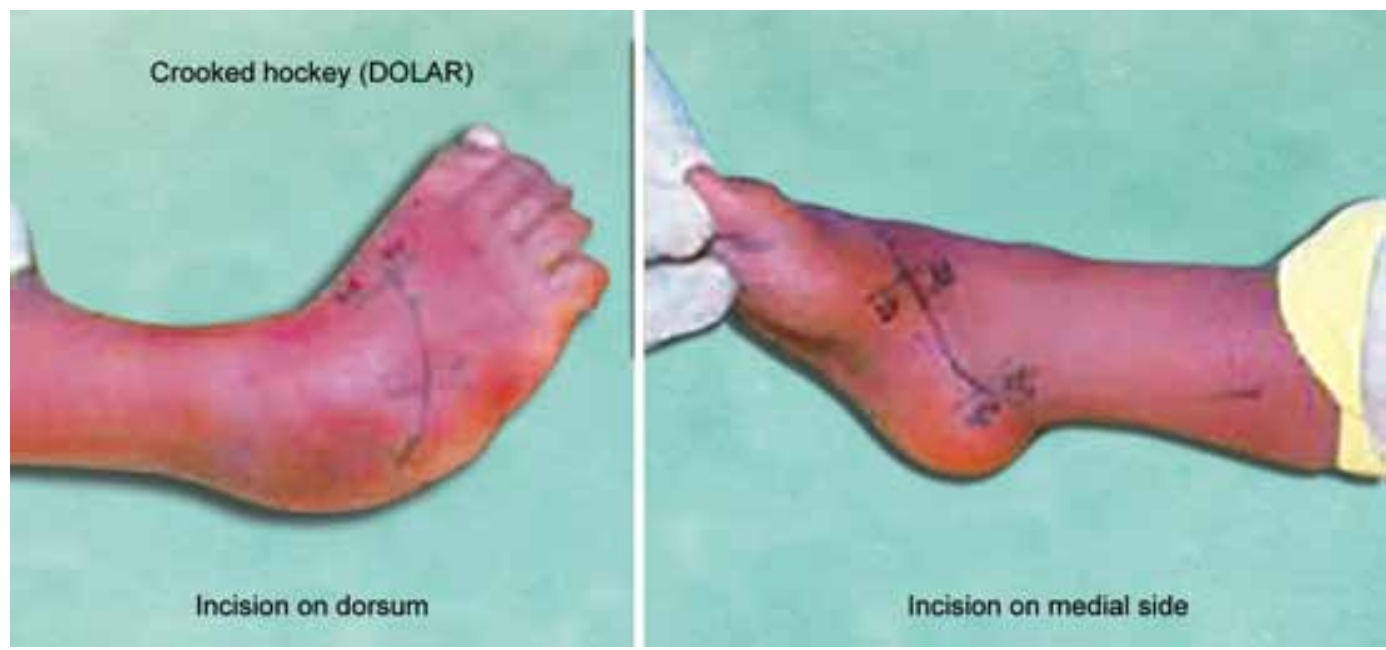

Fig. 2: Three-dimensional incision dorsolateral rotation skin flap
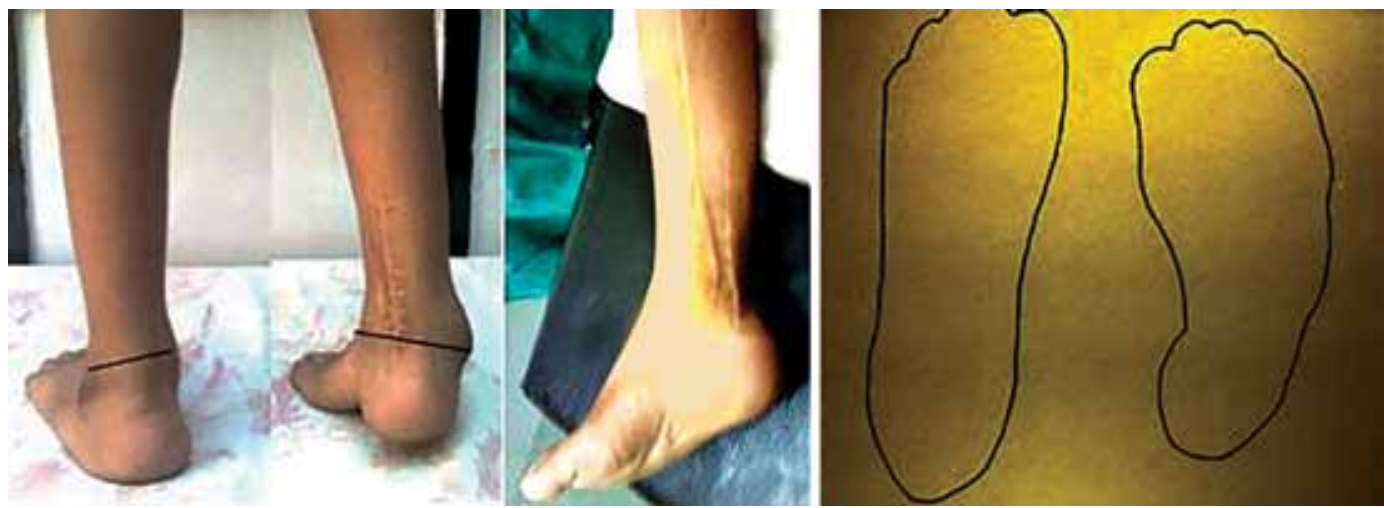

Fig. 3: Nine and half years old male with rigid deformity, keloid bow string scars of two earlier surgeries with widened ankle mortis
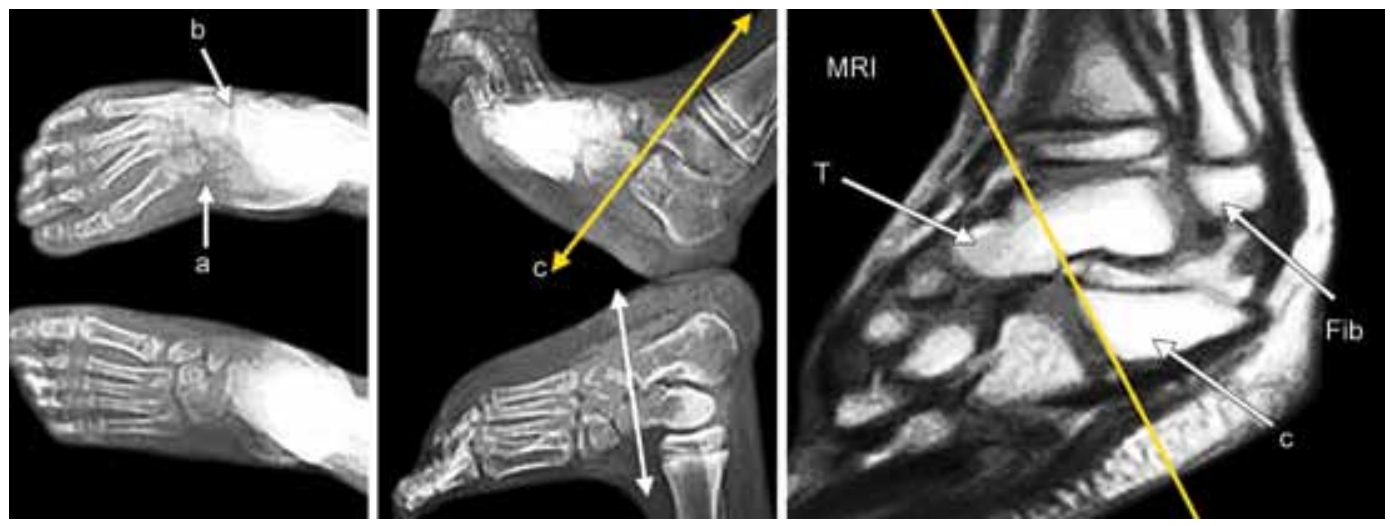

Fig. 4: X-rays and MRI showing flat-topped talus and triple plus dislocation (a: cuneonavicular, b: talonavicular, c: anterior dislocation talus at ankle and subtaloid with diastasis) 
dividing this ligament sufficiently but not completely, some tethers still remaining.

- Osseous correction: Osseous correction carried out was excision of a dorsolateral wedge from the cuboid and completing the osteotomy of cuboid to enable the two fragments to slide against each other (sliding osteotomy) to facilitate correction of the triple plus dislocations and tarsometatarsal mobilization (Kendrick et al 1970) to correct the rigid metatarsus varus.

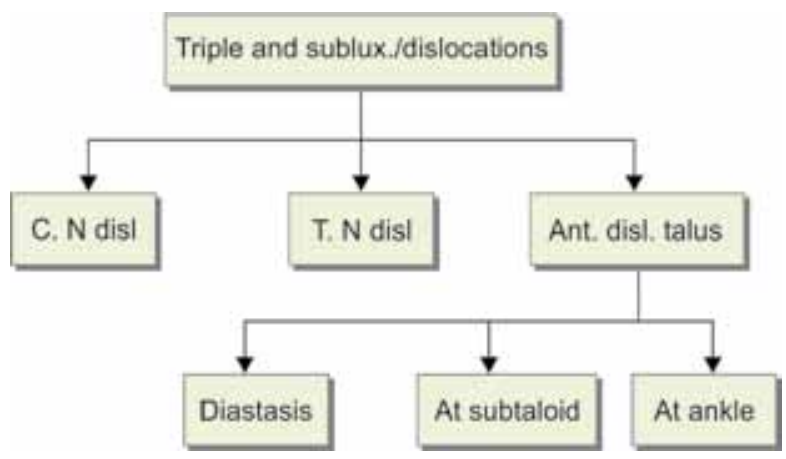

Fig. 5: Three additional components of anterior dislocation talus to make it triple plus instead of simple triple dislocation

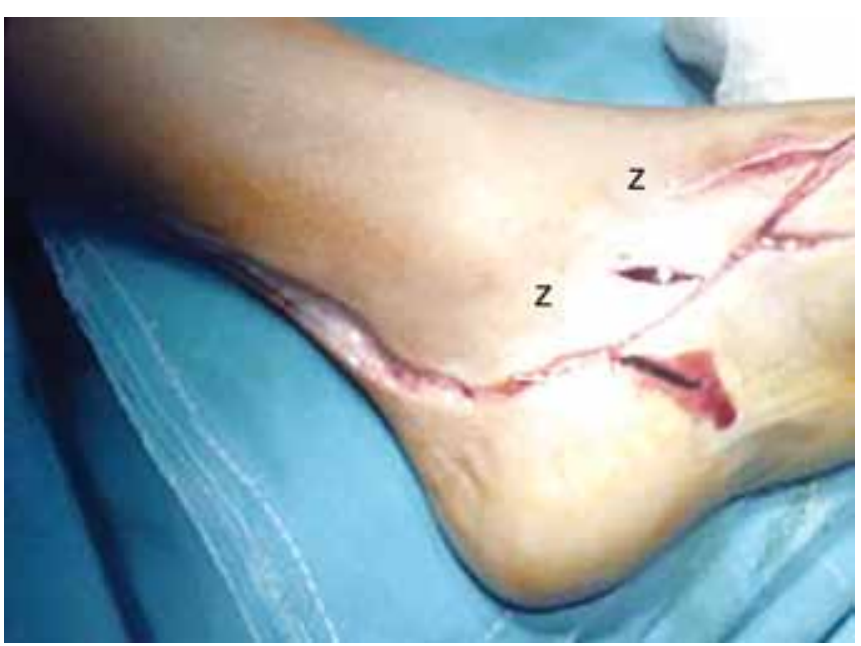

Fig. 6: Scars excised, Dolar and Z incision with two Z-plasties

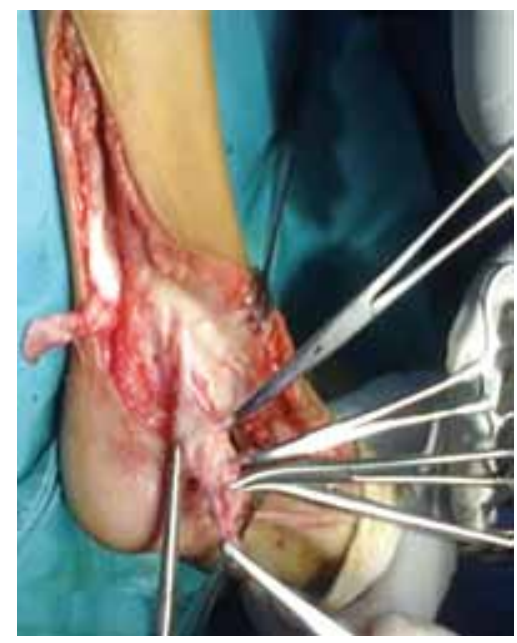

Fig. 8: All nine insertions of tibialis posterior dissected out and z-plasty of tendo achilles
- Final maneuver and K-wire fixation: Talar neck was pulled medially by a curved artery forceps hooked around its lateral side and, manipulating the foot into correction by bringing the navicular and medial cunieform in their normal positions and fixing the medial cuneiform and navicular with a K-wire from in front into the talus. Before fixing the wire, reduction of the triple plus dislocation must be ensured under vision. Wound closed meticulously to get a good scar. A well padded below knee plaster cast was applied after ensuring good circulation in the part.

- Postoperative care: Stitches were removed after 3 weeks and another plaster cast given for further 3 weeks with fully corrected deformity. Wound was completely healed now and correction was clinically excellent confirmed on X-rays. An elastic bandage was applied for another 3 weeks and the patient was allowed to walk in normal shoes with the advice of stretching exercises by sitting on both feet with heels touching the ground (a position needed for ADL in India). At 7 months follow-up, the correction of deformity was

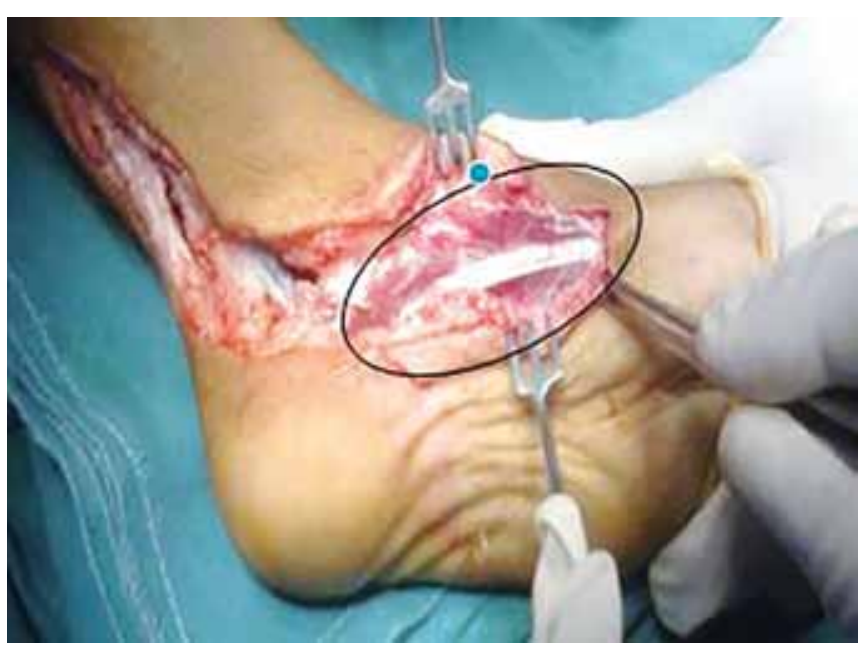

Fig. 7: Grossly hypertrophied abductor hallucis

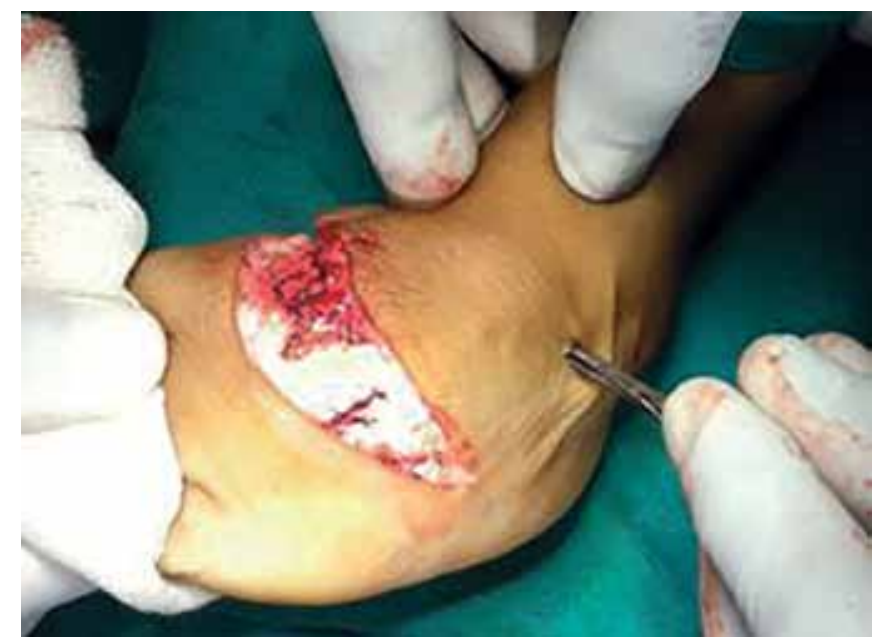

Fig. 9: Blind subtotal division of interosseous talocalcanean ligament with a stab knife 


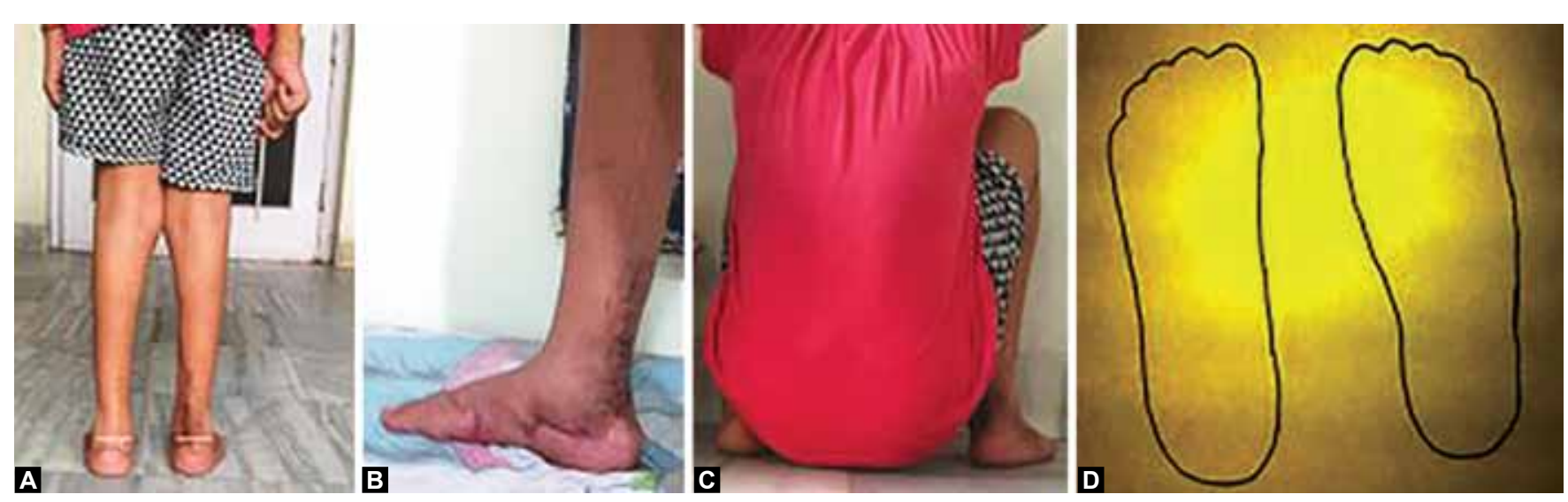

Figs 10A to D: At 7 months follow-up: (A) excellent correction from back with normal width malleoli, (B) from medial side healthy scar, (C) no hidden equinus on sitting on feet (ADL) and (D) normal foot print

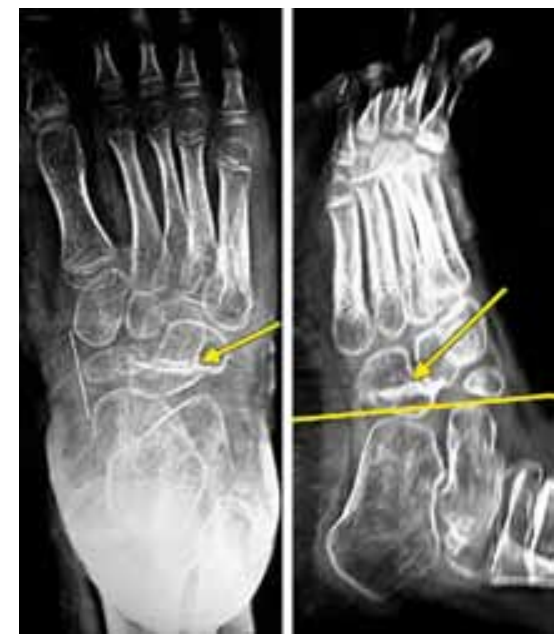

Fig. 11: Radiological correction of all triple plus dislocations normally aligned, united sliding osteotomy cuboid and restored talocalcanean angle at 7 months follow-up

excellent clinically, correcting even the hidden equinus essential in our country for ADL (Figs 10A to D) as well as radiologically (Fig. 11). Criteria for assessment of result in this case were healthy scar, full correction of deformity, supple foot without any hidden equinus.

\section{DISCUSSION}

This new surgical concept has been evolved for obstinate deformities like the present case, besides of course, in lots of others in older children, adolescents and even adults, seen frequently in our country and many other Asian countries. Thus, it is a need based and a completely evidence-based technique for step by step total correction. It is 3D deformity right from the skin to fascia, muscles, bones and joints and, therefore, a 3D concept of all round surgical correction has to be adopted for these diverse types of situations (obstinate deformities).

- Skin contracture: The two circle simulation diagram clearly demonstrates the skin contracture, besides the clinical evidence as described earlier. Scars of previous surgeries and age-related increase are further evidences. To correct this 3D contracture, a 3D incision has to be adopted as in this case. Addition of Z-plasties to the skin incision, not only provided lengthening of medial border of foot, but it also helped in reduction of all the dislocations due to available space and in closure of open wedge and sliding of fragments of cuboid osteotomy.

- Muscular contractures: Abductor hallucis was unusually hypertrophied, not seen earlier, deserving special attention and was released completely to slide forward. Steindler plantar release, for plantar fascia and flexor digitorum brevis, was essential to correct cavovarus. Tibialis posterior has been considered as the primary factor in the pathoanatomy of clubfoot and rest every thing can be explained on this basis. All nine strong and tenacious insertions pull these bones toward medial malleolus forcing all other soft tissues and bones to follow suit including the dislocations. Therefore, a complete meticulous division of each of its nine insertions was essential to open up the crouched foot bones. Tenotomy of flexor hallucis and flexor digitorum longus at the knot of Henry was essential to further correct cavovarus.

- Ligamentous contractures: Complete division of spring ligament, other plantar intertarsal ligaments and tarsometatarsal mobilization was essential to reduce all the dislocations and correct cavovarus. The blind division of interosseous talocalcanean ligament enables its subtotal division, which is more than partial (inadequate); but less than complete (aggressive leading to frequent valgus). ${ }^{8,9}$ Subtotal division allows sufficient movement of talus on calcaneum to be able to reduce talocalcanean dislocation and restore talocalcanean angle, but avoiding overcorrection. K-wire fixation is essential to maintain the reductions and it was needed for only 3 weeks.

- Pathogenesis of this unique pathoanatomy: Besides the severity, age-related and weightbearing factors, it is felt that iatrogenic factor in the form of dense adherent bow string keloid scars including that of conjoint 
posterior capsule, contributed to a greater extent. Due to constant weight bearing for 8 and half years and micropush at each step forward and medially, talus was pushed anteriorly due to pincer action of posterior ends of calcaneum and tibia and laterally by the navicular (indirectly by tibialis posterior pull) and this complex mechanics led to all these unusual dislocations including the mandatory diastasis. Ankle mortis normally being narrower in front, talus can not dislocate forward without diastasis.

- Innovative sliding osteotomy of cuboid: This was imperative to reduce these dislocations. The anterior part of foot with three cuneiforms and distal fragment cuboid osteotomy acting as one segment and all other tarsals as the other segment to move and reduce the dislocations, starting from medial cuneiform. However, it was the collective effect of all the operative steps. A K-wire fixation for 3 weeks was essential to maintain the reduction.

Special attention to every single factor of pathoanatomy is essential to correct the complex deformity. Awareness is very important, may be such a defect is more frequent with long persistent deformities, especially after repeated surgeries.

\section{REFERENCES}

1. Flinchum D. Pathological anatomy in talipes equinovarus. J Bone Joint Surg Am 1953;35(1):111-114.

2. Fried A. Recurrent congenital club foot. The role of M. tibialis posterior in etiology and treatment. J Bone Joint Surg Am 1959;41(2):243-252.

3. Stewart SF. Club foot; its incidence, causes and treatment: an anatomical physiological study. J Bone Joint Surg Am 1951;33(3):577-590.

4. Shapiro F, Glimcher MJ. Gross and histological abnormalities of the talus in congenital club foot. J Bone Joint Surg Am 1979;61(4):522-530.

5. Irani RM, Sherman MS. The pathological anatomy of club foot. J Bone Joint Surg Am 1963;45(1):45-52.

6. Settle GW. The anatomy of congenital talipes equinovarus (sixteen dissected specimens). J Bone Joint Surg Am 1963; 45(7):1341-1354.20.
7. Bechtol CO, Mosman HW. Club foot an embryological study of associated muscle abnormalities. J Bone Joint Surg Am 1950;32(4):827-838.

8. Turco VJ. Resistant congenital club feet. One stage posteromedial release with internal fixation. J Bone Joint Surg 1979;61(6):805-814.

9. Simons GW. Complete subtalar release in club feet. J Bone Joint Surg 1985;67(7):1044-1065.

10. Hippocrates. Great books of the Western World. Chicago: Encyclopaedia Britannica; 1952;10. p.114.

11. Ponseti IV, et al. Treatment of the complex idiopathic clubfoot. Clin Orthop Relat Res 2006 Oct;451:171-176.

12. Evans D. Relapsed club foot. J Bone Joint Surg Br 1961;43(4): $722-733$.

13. Kendrick RE, Sharma NK, Hassler W, Herndon CH. Tarsometatarsal mobilisation for resistant adduction of fore part of foot. J Bone Joint Surg Am 1970;52(1):61-70.

14. Steytler JCS, Vander Walt ID. Correction of resistant adduction of the forefoot in congenital club foot and congenital metatartus varus by metatarsal osteotomy. Br J Surg 1966;53(6): 558-560.

15. Sheldon L. A medial and lateral release operation for club foot: a preliminary report. Clin Orthop Relat Res 1972;84(7): 197-200.

16. Main BJ, Crider RJ, Polk M, Lloyd Roberts GC, Swan M, Kamdar BA. The results of early operation in talipes equinovarus. J Bone Joint Surg Br 1977;59(2):337-441.

17. Golyakhovsky V, Frankel VH. Operative manual. 1st ed. Ilizarov technique for correcting foot deformities 1993;205213.

18. Ganger R, Radler C, Handlbauer A, Grill F. External fixation in clubfoot treatment: a review of the literature. J Paediatr Orthop B 2012 Jan;21(1):52-58.

19. Usuelli FG, Lastroni G, Grassi M, Malerba F. Talectomy in a neglected club foot in Zambia: a low cost one step option in a developing country. J Foot Ankle Surg AP 2014 Jan-Jun; 1(1):32-33.

20. Beatson RR, Pearson JR. A method of assessing correction in club foot. J Bone Joint Surg 1966;48B(1):40-50.

21. Bertelson A. Treatment of congenital club foot. J Bone Joint Surg 1957;39(3):599-604.

22. Mittal RL, Makhni SS, Sidhu GS. Morbid anatomy of congenital club foot. Ind J Orthop 1981;15(2):129-135.

23. Mittal RL. The surgical management of resistant club foot by rotation skin flap and extensive soft tissue release. Int Orthop (SICOT) 1987;11(3):189-192. 